\title{
ESPORTE E POLÍTICAS SOCIAIS NO BRASIL: UMA DISCUSSÃO SOBRE CIDADANIA E EMANCIPAÇÃO HUMANA
}

\author{
Pedro Avalone Athayde \\ Universidade de Brasília, Brasília, Distrito Federal, Brasil \\ Felipe Barbosa Passos \\ Universidade de Brasília, Brasília, Distrito Federal, Brasil
}

\begin{abstract}
Resumo
Este artigo caracteriza-se como um ensaio teórico sob uma perspectiva crítica e dialética da relação entre esporte e políticas sociais, referenciada em clássicos da literatura políticofilosófica, bem como em autores contemporâneos. O objetivo desse estudo é teorizar os conceitos de cidadania (na perspectiva de Marshall) e emancipação humana à luz de referências do materialismo-dialético, observando a relação entre esporte e políticas sociais. Após esse exercício teórico-analítico, observamos que a cidadania não é criação subjetiva, mas sim uma vivência e uma construção histórica a partir do acesso a determinados bens políticos, sociais e culturais. Assim, a luta pelo acesso ao esporte como direito apresenta-se como elemento constituinte do processo emancipatório.
\end{abstract}

Palavras-chave: Esporte. Política Social. Cidadania. Emancipação Humana.

\section{SPORT AND SOCIAL POLICIES IN BRAZIL: A DISCUSSION ABOUT CITIZEN- SHIP AND HUMAN EMANCIPATION}

\begin{abstract}
This article is characterized as a theoretical essay from a critical and dialectical perspective of the relationship between sport and social policies, referenced in classics of the politicalphilosophical literature, as well as in contemporary authors. The purpose of this study is to theorize the concepts of citizenship (in Marshall's perspective) and human emancipation in the light of dialectical-materialism works, observing the relationship between sport and social policies. After this theoretical-analytical exercise, we observe that citizenship is not a subjective creation, but rather an experience and a historical construction based on access to certain political, social and cultural goods. Thus, the struggle for access to sport as a right presents itself as a constituent element of the emancipatory process.
\end{abstract}

Keywords: Sport. Social Policy. Citizenship. Human Emancipation.

\section{DEPORTES Y POLÍTICAS SOCIALES EN BRASIL: UNA DISCUSIÓN SOBRE CIUDADANÍA Y EMANCIPACIÓN HUMANA}

\section{Resumen}

En este artículo se caracteriza por ser una prueba teórica en una perspectiva crítica y dialéctica de la relación entre el deporte y las políticas sociales que se hace referencia en la literatura política-filosófica clásica, así como los autores contemporáneos. El objetivo de este estudio es 
teorizar conceptos de ciudadanía [la perspectiva de Marshall] y la emancipación humana a la luz de las referencias materialismo dialéctico, teniendo en cuenta la relación entre el deporte y las políticas sociales. Después de este ejercicio teórico y analítico, hemos observado que la ciudadanía no es la creación subjetiva, sino una experiencia y un edificio histórico del acceso a determinados activos político, social y cultural. Por lo tanto, la lucha por el acceso al deporte como un derecho se presenta como un elemento constitutivo del proceso emancipador.

Palabras clave: Deporte. La Política Social. La Ciudadanía. La Emancipación Humana.

\section{Introdução}

Aparentemente, esporte e cidadania localizam-se em campos semânticos afastados. No entanto, esse distanciamento aparente transforma-se em aproximação recorrente na narrativa dos objetivos e princípios que - comumente - regem os projetos sociais esportivos, em que o esporte é apresentado como instrumento com potencial de formação e promoção do exercício da cidadania. Essa visão idealista é edificada por representações mentais de uma realidade concreta formada por vínculos de inserção imediata (IASI, 2011), que percebem o fenômeno esportivo e a condição cidadã como naturalmente positivos.

Pressupomos, assim, que a reprodução de investigações com enfoques restritos ou unilaterais pode ensejar equívocos de ordem teórico-metodológica. Diante desse pressuposto, a proposta deste ensaio é problematizar os conceitos de cidadania (tendo como pano de fundo a perspectiva de Marshall) e emancipação humana à luz de referências do materialismodialético, olhando para a relação entre esporte e políticas sociais.

Pela sua natureza e estrutura, reconhecemos este artigo como um ensaio ou pesquisa teórica. Trata-se de uma problematização teórico-conceitual das políticas sociais esportivas a partir de referencial bibliográfico que mescla clássicos da literatura política-filosófica e autores de destaque na contemporaneidade. Como recurso de ilustração e aproximação à dimensão empírica, recorremos - no final do texto - a aproximações com uma política esportiva vigente, o Programa Segundo Tempo (PST), executado pelo Ministério do Esporte.

O ensaio inicialmente apresenta uma discussão conceitual sobre cidadania, problematizando as proposições teóricas de T.H. Marshall. Posteriormente, tendo como referência principal o texto clássico de Marx - Sobre a questão judaica, debate o significado de emancipação humana, diferenciando-a da (emancipação) política, cujo caráter restringe-se às fronteiras dessa sociabilidade. Na sequência, apresentamos as relações desses temas com o esporte e a política social. Por fim, realiza exercício teórico de indagação acerca das potencialidades/contribuições do esporte na busca pela emancipação humana.

\section{Cidadania, política social e emancipação humana}

\section{Discussões conceituais sobre Cidadania}

A concepção de Marshall a respeito da cidadania se sustenta nas premissas de que ela atinge sua plenitude no século XX devido à convivência entre as três gerações de direitos - $\mathrm{o}$ civil, o político e o social -, e que essa "plena" cidadania seria um fator impactante para a redução da desigualdade social. Essa visão suscita indagações: o que é cidadania para Marshall? Quais são os limites do seu conceito de cidadania? Qual a relação entre cidadania e desigualdade social?

O livro Cidadania, classe social e status, publicado no Brasil em 1967, tornou-se uma referência no debate sobre direitos e cidadania. Nesta obra, Marshall (1967, p. 76) concebe a cidadania como "um status concedido àqueles que são membros integrais de uma comunida- 
de. Todos aqueles que possuem o status são iguais com respeito aos direitos e obrigações pertinentes ao status". O alcance dessa condição vincula-se aos direitos, que, na perspectiva do autor, seguem uma progressividade histórica (direitos civis no século XVIII, os políticos no século XIX e, por último, os sociais no século XX). Vale ressaltar que trata-se de uma construção evolutiva linear, concebida a partir da realidade britânica, que, portanto, deve ser confrontada com a particularidade histórica de cada país.

Para Marshall, a cidadania é almejada (idealmente) nas sociedades modernas, sendo considerada uma medida de igualdade social. Dito de outra forma, a igualdade estaria relacionada à quantidade de indivíduos inseridos no status de cidadão e no fortalecimento dos direitos. A classe social, em outra direção, diz respeito ao sistema de desigualdade.

A questão principal da teoria de Marshall (1967, p. 51) "é que até o final do século XIX, a cidadania ainda não tinha impactado sobre a desigualdade de classe porque lhe faltava um elemento determinante - os direitos sociais - que só viriam a conhecer um desenvolvimento mais efetivo a partir do século XX". Inicialmente, o sistema de classe social não sofrerá impacto da cidadania devido à sua "incompletude", pois apenas os direitos civis e políticos eram garantidos e eles de certa forma se alinhavam ao sistema capitalista. Em outras palavras, os direitos civis eram indispensáveis ao livre mercado, pois asseguravam a liberdade individual e garantiam a propriedade privada; e os direitos políticos, mesmo sendo uma ameaça potencial ao capitalismo, ainda não eram um instrumento dominado pela classe trabalhadora para tencionar contra a burguesia (BOSCHETTI, 2016).

É importante sublinhar que Marshall (1967) considerava a desigualdade como necessária à sociedade e não se opunha ao sistema de classes, apenas à excessiva desigualdade. Segundo Boschetti (2016, p. 54), a principal conclusão de Marshall é que "a cidadania, ao incluir os direitos sociais, passou a alterar o padrão de desigualdade social no capitalismo e provocar influências profundas sobre a estrutura de classes a partir do século XX, sem, contudo, ter o propósito de acabar com a desigualdade". Essa análise é confirmada pelo próprio autor, para quem os direitos sociais deveriam "diminuir o ônus da pobreza sem alterar o padrão da desigualdade do qual a pobreza era, obviamente, a consequência mais desagradável" (MARSHAL, 1967, p. 88).

Na sequência da breve exposição sobre o conceito de cidadania em Marshall, faremos o caminho inverso para desvelar suas contradições e apontar suas limitações. Nesse itinerário, adotamos as análises de Barbalet (1989), iniciando por sua crítica sobre a necessidade de situar historicamente o conceito de cidadania. Isso porque a cidadania não é algo abstrato ou atemporal, mas um fenômeno circunscrito à dinâmica desta sociedade e determinado pelos elementos constitutivos desta sociabilidade. Essa ponderação coaduna com os apontamentos de Abreu (2008), para quem a cidadania moderna não pode ser pensada apartada das condições de existência da sociedade, mas sim avaliada a partir das condicionalidades impostas pela hegemonia do capital.

Barbalet (1989) advoga a necessidade de desmistificar a abordagem fundamentada no desenvolvimento histórico dos direitos como uma evolução natural do sistema capitalista e salienta o importante papel da luta de classe como indispensável nesse processo. Isto significa que os direitos de cidadania não são derivações do próprio capitalismo e da sua "evolução", mas sim o resultado da "tensão social" entre capital e trabalho.

Segundo Abreu (2008), a concepção de Marshall de cidadania limita-se à "igualdade de status" e à "participação na vida civilizada". Isso significa que os direitos sociais ou a cidadania social defendida pelo autor são uma igualdade de oportunidades, que não se opõem ou criticam a desigualdade social em si - exceto quando ela é excessiva. Conforme destacamos anteriormente, Marshall defende que os direitos sociais podem afetar a estrutura da desigualdade social, entretanto, essa situação não ocorreria essencialmente pelos rendimentos financeiros advindos do trabalho, mas por meio dos serviços sociais. Para ele, o relevante é 
"que haja um enriquecimento geral da substância concreta da vida civilizada, uma redução geral do risco e insegurança, uma igualação entre os mais e menos favorecidos em todos os níveis [...]. A igualdade de status é mais importante que a igualdade de renda" (MARSHALL, 1967, p. 94-95). Neste contexto, Boschetti (2016, p. 53) afirma que os direitos sociais da cidadania marshalliana têm a clara intenção de garantir "mínimos sociais, a partir dos quais, cada cidadão, tendo reconhecido o status de cidadão, ou da igualdade formal, deve ir além e buscar melhores condições por mérito e esforço próprio, ou seja, competindo no mercado".

Depreende-se que a cidadania nos contornos da sociedade burguesa se limita a sujeitar o indivíduo à divisão de classes como a única formação social possível. Abreu (2008) conclui que Marshall preocupa-se fundamentalmente com a manutenção do status quo, por meio da estabilização e legitimação da sociedade de classes e da ordem social vigente. Tais objetivos pressupõem o equacionamento das desigualdades sociais fundadas na divisão social e técnica do trabalho pelo sofisma da "igualdade de status" como preceito da cidadania. Finalmente, observa-se que Marshall, ao naturalizar a desigualdade social como inerente à sociedade, expõe de modo muito claro os limites da cidadania: a sociedade capitalista!

\section{Traços de distinção entre emancipação humana e emancipação política}

Assim como Coutinho (1999), reconhecemos que as elaborações teóricas de Marshall contribuíram para delimitar as três determinações "modernas" da cidadania (civil, política e social) e atribuir uma dimensão histórica ao debate. Entretanto, suas limitações aparecem quando pensamos em uma cidadania plena caracterizada pela socialização da riqueza social e materialmente produzida, ou seja, a emancipação humana. Nesse sentido, faz-se necessário apresentarmos nossa compreensão acerca dessa dimensão emancipatória, diferenciando-a daquela que se circunscreve à esfera política.

Karl Marx (2010), em seu artigo Sobre a questão judaica, traz uma nova perspectiva a respeito não apenas da religião e do "lugar" dos judeus na sociedade alemã, mas dos limites da emancipação política. De acordo com Marx (2010), trata-se de uma emancipação restrita aos pilares da sociedade burguesa, quais sejam: a propriedade privada, o Estado político e a cidadania. Nesse sentido, Iasi (2011, p. 47) registra que a discussão sobre o tema da emancipação humana em contraposição à insuficiência da emancipação política nos conduz a questionar se "os limites da sociedade atual e das instituições da ordem burguesa representariam a forma definitiva enfim encontrada pela humanidade para sua sociabilidade?". A essa questão não há resposta simples e unívoca, e refletir sobre ela extrapolaria em muito os limites desse texto.

Marx (2010, p. 38-39) identifica que a deficiência da emancipação política reside "no fato de o Estado ser capaz de se libertar de uma limitação sem que o homem realmente fique livre dela, no fato de o Estado ser capaz de ser um Estado livre sem que o homem seja um homem livre". Portanto, os direitos alcançados na sociedade burguesa estão restringidos às determinações dessa organização social. Face ao exposto, infere-se que a emancipação política não deve ser considerada uma etapa anterior à emancipação humana, uma vez que não altera a estrutura da relação capital/trabalho. Em última instância a emancipação política corresponde ao limite da condição de acesso a direitos formais na sociabilidade vigente.

De acordo com Marx (2010), a plena realização da emancipação humana ocorrerá quando o homem individual real for aquele que tem direitos substantivos e condições reais de exercê-los. Ademais, isso exigiria uma sociedade emancipada da exploração do capital, na qual o homem sairia da condição de cidadão formal - em que todos são iguais perante a lei, mas não há igualdade substantiva - e recuperaria para si o cidadão abstrato ou aquele que se relaciona orientado pelas necessidades humanas. Não obstante os limites ora apontados, Marx 
(2010) reconhece a importância histórica da emancipação política como sendo o mais próximo da emancipação humana dentro das condições materiais de existência.

Na concepção marxiana, a emancipação humana teria a capacidade de revelar aos seres humanos a história como fruto da ação humana e conduzi-los a assumir o controle consciente de sua existência. Todavia, o próprio Marx reconhece que os seres humanos não fazem história como querem devido às limitações impostas pelas determinações da vida material, o que torna a emancipação política um importante e indispensável instrumento de pressão contra o capital e de mobilização da classe trabalhadora, que, a princípio, pode ocorrer em três frentes: (i) política: como uma forma de organização da classe trabalhadora na luta, a princípio, por direitos de cidadania - saúde, previdência, educação, esporte -, mas que não deve se esgotar nesse horizonte e, sim, na conscientização política pela emancipação humana; (ii) na reprodução da classe trabalhadora: por assegurar melhores condições de vida aos trabalhadores, por exemplo, são muito melhores as condições de vida hoje que no século XIX; (iii) ideológica: por meio da emancipação política e do que ela propicia - acesso à educação, formação de partidos políticos, associativismo, cultura - é possível construir uma consciência crítica sobre a própria sociedade capitalista, isto é, sem a emancipação política seria difícil qualquer espaço para debater ou pensar diferente.

\subsection{Relações entre política social e cidadania}

As discussões sobre a emancipação humana e política, ao fim e ao cabo, nos conduzem a reflexões mais abrangentes acerca dos marcos da sociabilidade vigente. Entretanto, tais conceitos também possuem uma dimensão mais tangível e visível. Nessa dimensão mais restrita, relacionam-se com as ações do Estado nas áreas sociais, que se consubstanciam em uma proposta de política social, que, por vezes, apresenta como diretriz a ampliação e o exercício da cidadania.

A gênese das políticas sociais no capitalismo central vincula-se ao reconhecimento político do Estado da questão social ${ }^{1}$. No século XIX predominava o liberalismo clássico do laissez faire, porém o século seguinte foi marcado por mudança na morfologia do Estado, "que abrandou seus princípios liberais e incorporou orientações socialdemocratas num novo contexto socioeconômico e de lutas de classes, assumindo um caráter mais social, com investimentos em políticas sociais" (PISÓN, 1998 apud BEHRING; BOSCHETTI, 2011, p. 63). Essa transformação não reflete uma evolução natural do Estado liberal para um social, mas sim a consequência de diversos fatores que têm como eixo a luta da classe trabalhadora pela emancipação política, de um lado, e, de outro lado, as mudanças estruturais do capitalismo no decorrer dos séculos XIX e XX, bem como o crescimento do papel integrador do Estado.

Um dos elementos que demarcam a emergência das políticas sociais é que elas passaram a ampliar a ideia de cidadania ao redirecionar suas ações para além da pobreza extrema. Assim, ocorreu uma mudança na relação do Estado com o cidadão na direção de: (i) incorporar nas ações estatais parte das necessidades sociais reivindicadas pelos trabalhadores; (ii) reconhecer legalmente os seguros sociais como um conjunto de direitos e deveres; (iii) legitimar os direitos sociais como elementos da cidadania; e (iv) aumentar o investimento público nas políticas sociais (BEHRING; BOSCHETTI, 2011).

No que concerne às relações entre política social e cidadania, Barbalet (1989) apresenta duas questões importantes: a primeira é que não se pode criar uma equivalência ou relação direta entre direitos e políticas sociais. Nos marcos dessa sociedade, recorrentemente aqueles que mais precisam dos serviços sociais são os que enfrentam maiores dificuldades para aces-

\footnotetext{
${ }^{1}$ Que encontra explicação na dualidade entre capital e trabalho, ou melhor, na lógica de apropriação privada da riqueza construída coletivamente, sendo as mazelas que daí surgem expressões desta causa fundante (IAMAMOTO, 2013).
} 
sá-los como direito. A título de exemplo, basta olharmos para as insuficiências e barreiras das políticas públicas de saúde em nosso país.

A segunda questão refere-se à reflexão sobre a possibilidade de que os direitos sociais constituam direitos de cidadania e universais. Há possibilidade de universalização dos direitos sociais numa sociedade capitalista? Para Barbalet (1989), a cidadania nesta sociedade prima pelos direitos civis e políticos, buscando-se a universalidade deles (quando interessantes às classes dominantes). Entretanto, os direitos sociais e o acesso desigual a eles não são uma preocupação de primeira ordem, sendo até negados muitas vezes sem ofender a estrutura desta sociedade.

A perspectiva universal do acesso aos direitos sociais, absorvida na proposta de Marshall, nos conduziria à imagem de um Estado responsável por oferecer a todos os cidadãos serviços sociais como direitos. Embora essa configuração tenha acontecido em determinados países em conjunturas históricas particulares e em políticas específicas (proteção social), o tempo nos mostra que elas não se sustentaram no longo prazo, pois colidem com as determinações do próprio capitalismo.

Barbalet (1989) pondera que os direitos civis e políticos podem ser facilmente materializados pela igualdade formal limitada à esfera legal, sem modificar as condições individuais, ou melhor, sem modificar as relações econômicas e de classe. No entanto, os direitos sociais não podem conferir segurança econômica numa base universal, pois não é suficiente a positivação legal, a qual demanda uma materialização (e possui custos consideráveis e sistemáticos) diferente dos outros direitos.

Assim, as políticas sociais como forma de materializar direitos sociais não terão características universais, mas sim de mínimos sociais e de uma ação focalizada com a finalidade de minorar ou readequar expressões da questão social inerentes à sociedade capitalista e, dessa forma, integrar as classes dominadas. A despeito dessa configuração, as políticas sociais ainda constituem espaço de atuação contra hegemônica de mobilização e ganhos dos trabalhadores, tendo no horizonte ideopolítico a emancipação humana.

Nesta última questão, Coutinho (2008) faz uma importante defesa dos direitos sociais e das políticas sociais como elementos essenciais na luta de classes, fazendo jus à categoria da contradição. Primeiramente, ele refuta a lógica mecanicista de parte da tradição marxista de que as políticas sociais atendem unicamente às necessidades do capital e servem apenas para legitimar a ordem burguesa.

[...] Essa posição, por ser unilateral, é equivocada. Como todos os âmbitos da vida social, também a esfera das políticas sociais é determinada pela luta de classes. Através de suas lutas, os trabalhadores postulam direitos sociais que, uma vez materializados, são uma indiscutível conquista; mas isso não anula a possibilidade de que, em determinadas conjunturas, a depender da correlação de forças, a burguesia use as políticas sociais para desmobilizar a classe trabalhadora, para tentar cooptá-la. (2008, p. 87-88).

Esta lógica de ampliação dos direitos de cidadania como uma forma de fortalecer a classe trabalhadora e resistir frente ao capital é sustentada por Coutinho (2008, p. 67) como uma "possibilidade concreta de obter transformações sociais substantivas através de refor$\operatorname{mas}^{2}$ ". Face ao exposto, consideramos a defesa pelas políticas sociais e a ampliação dos direitos de cidadania não como um fim em si mesmo, mas como parte de um árduo processo histórico e dialético de avanços e retrocessos para os trabalhadores.

\footnotetext{
${ }^{2}$ Não consideramos nesta assertiva de Coutinho a possibilidade dessas transformações serem uma forma de elevar a classe trabalhadora à emancipação humana, mas como uma forma de mediação por melhores condições de vida e de organização política dos trabalhadores. 


\section{Esporte, política social e cidadania no Brasil}

Inicialmente, situaremos o esporte historicamente para não incorremos no erro de um debate superficial e genérico sobre o tema. Nesse sentido, apresentamos a seguinte indagação: qual é a gênese do esporte? $?^{3}$

Reconhecemos que não há um consenso na área (da Educação Física) sobre a resposta à questão acima. No entanto, adotaremos o entendimento do esporte moderno como um produto da modernidade, erigido juntamente com a configuração de uma sociedade urbanoindustrial, mais especificamente no contexto europeu na transição entre os séculos XVIII e $\mathrm{XIX}^{4}$. Ademais, compreendemos o esporte como um fenômeno cultural resultante da produção humana para atender necessidades mutáveis e socialmente construídas, o que atribui um caráter de transitoriedade e reconfiguração das funções sociais do esporte.

Observando a realidade brasileira no que se refere ao esporte e mais precisamente às relações normativas estabelecidas pelo Estado, temos, desde as primeiras legislações esportivas (BRASIL, 1941) e passando pelas do período da ditadura civil-militar (BRASIL, 1975), uma relação entre o Estado e o esporte "que caracterizou uma presença interventora, de caráter conservador, do Estado no esporte. [...] Esse caráter permanecerá até a década de 90. Daí em diante teremos outra configuração da presença do Estado no âmbito esportivo" (CASTELLANI FILHO, 2008, p. 136).

A lógica que se instaurou no esporte após a Constituição de 1988 foi a de liberalização do esporte das "amarras" do Estado para se modernizar e se adequar às regras do mercado, assumindo o signo da mercadoria. Dentro dessa transformação, recuperaram autonomia e importância as entidades de administração esportiva ${ }^{5}$.

A Constituição de 1988, ao prever em seu artigo 217 que "é dever do Estado fomentar práticas desportivas formais e não formais, como direito de cada um" (BRASIL, 2005), traz um avanço - ao menos no campo formal (lembremo-nos de Marshall) - para as possibilidades de acesso ao esporte pelos brasileiros. Durante a década de 1990, o reconhecimento desse direito é colocado em segundo plano em relação ao projeto de liberalização esportiva. No entanto, a partir de 2003, mas precisamente em 2005 (com a Política Nacional de Esporte), o Ministério do Esporte, principal órgão gestor das políticas esportivas do país, reconhece o esporte como um direito social.

Neste momento histórico, temos dois acontecimentos marcantes: o primeiro refere-se à retomada do sentido da responsabilização estatal e do papel ativo do Estado (social) na garantia dos direitos. Já o segundo aspecto versa sobre o reconhecimento do esporte como um "direito", na tentativa de avançar além da positivação legal deste direito, incorporando-o à perspectiva de uma cidadania ampliada, o que promoveria mudanças significativas no seu acesso. Isso poderia se dar, por exemplo, pela consolidação de uma estrutura sistêmica, democrática, transparente e programática capaz de assegurar o acesso universal, em contraponto a uma estrutura piramidal e seletiva. Entretanto, a direção das alterações ganhou o rumo determinado pelas frações de classe hegemônicas no esporte e seus interesses particularistas.

\footnotetext{
${ }^{3}$ Para maior aprofundamento sobre o tema sugerimos as obras de Bracht (2005), Proni (1998), Brohm (1982) e Rouyer (1977).

${ }^{4}$ Isso não significa que não reconheçamos outras interpretações - inclusive no âmbito da Educação Física - que vinculem a prática esportiva às expressões corporais e ritualísticas de sociedades ligadas à Antiguidade.

5 Para Castellani Filho (2008, p. 136), o esporte após a Constituição de 1988 sai do domínio direto do Estado e vai para o mercado "tendo por sustentáculo as entidades com personalidade jurídica de direito privado [federações esportivas]. Uma entidade com personalidade jurídica de direito privado que não permite, em nome de sua autonomia, a presença do Estado. Uma entidade que não admite a intervenção do Estado, mas só funciona com recurso público; não consegue funcionar sem o dinheiro público, não vive sem dinheiro público, portanto vive o melhor dos mundos"!
} 
As políticas sociais esportivas que propunham materializar o esporte como um direito e visavam promover o acesso democrático a este bem social no período pós-constitucional foram tímidas e fragmentadas nos governos FHC (VERONEZ, 2005) e ampliadas (com ressalvas) nos governos Lula e Dilma - estes últimos, marcados pela perspectiva dos megaeventos esportivos e da maximização de dividendos econômicos a partir de uma visão do esporte parametrizada pela esfera do mercado (do consumo) em detrimento de políticas públicas de acesso democrático a todos os brasileiros.

Considerando esse contexto, indagamo-nos se as políticas sociais esportivas deste período, como uma forma de materializar o esporte enquanto um direito social, se alinham à perspectiva de cidadania proposta por Marshall. Essa reflexão ocorre, essencialmente, por três ilações: (i) essas políticas não possuem, quando materializadas na realidade social, a capacidade de proporcionar acesso a todos, ou melhor, não têm a intenção de acabar com o acesso desigual à prática esportiva, apesar da retórica; (ii) elas não combatem a desigualdade estrutural da sociedade, sendo em última instância um importante instrumento de coesão social, fortalecendo a função integradora ${ }^{6}$ do Estado; (iii) associam-se à ideia de mínimos sociais, ou seja, as política sociais esportivas são direcionadas, principalmente, às áreas de maior pobreza no Brasil, e para os que não se encontram nesta situação o acesso se dará pela comercialização de um serviço (esportivo), seja na vivência de uma prática esportiva, seja na dimensão da fruição de um evento (espetáculo) esportivo.

Para ilustrar estas mediações entre a perspectiva de cidadania de Marshall e as políticas sociais esportivas na realidade brasileira, utilizaremos como exemplo o Programa Segundo Tempo ${ }^{7}$ (PST) do Ministério do Esporte (ME). O PST foi considerado o principal programa social esportivo do governo federal, sobretudo na primeira gestão do Ministério do Esporte até o ano de 2007, e se destina a promover o "desenvolvimento integral de crianças, adolescentes e jovens como fator de formação da cidadania e melhoria da qualidade de vida, prioritariamente, daqueles que se encontram em áreas de vulnerabilidade social e regularmente matriculados na rede pública de ensino" (BRASIL, 2014, p. 6, grifo nosso).

O entendimento do esporte como um "fator de formação da cidadania" busca legitimálo perante a sociedade e a opinião pública por meio de associações diretas e superficiais entre o esporte e a cidadania, permeadas por um pensamento discriminatório quanto ao público a que se destina o esporte - os que "perderam" sua cidadania. A nosso ver, a cidadania não é algo a ser formado no interior dos indivíduos, pois eles já possuem o "status de membros da comunidade" (no caso, a brasileira), isto é, todos já são cidadãos. Em outras palavras, não se cria cidadania nos indivíduos; ela é vivenciada a partir do acesso a determinados bens políticos, sociais e culturais. O que nos leva a crê que há, na verdade, diferentes formas de vivenciar a cidadania. Assim, cabe a reflexão quanto a esta lógica: como o esporte irá formar algo que já existe nos indivíduos? Se o acesso ao esporte é direito de cidadania, como políticas sociais focalizadas irão possibilitar o acesso equânime deste bem cultural aos brasileiros?

Conforme anunciamos, a cidadania burguesa é vivenciada na sua universalidade nas esferas civis e políticas. No entanto, na esfera social ela ocorre de forma predominantemente focalizada e/ou mínima. A referência minimalista no caso do PST está na sua priorização das áreas de vulnerabilidade e risco social. Dessa forma, levantamos a seguinte reflexão: o PST e programas similares são - de fato - uma ponte para "formar" cidadãos, ou, ao contrário, con-

\footnotetext{
${ }^{6}$ Para Mandel (1982, p. 334) o Estado possui três funções básicas: reprimir, integrar e criar as condições gerais de produção. A função integradora a que nos referimos significa "integrar as classes dominadas, garantir que a ideologia da sociedade continue sendo a da classe dominante e, em consequência, que as classes exploradas aceitem sua própria exploração sem o exercício direto da repressão contra elas (porque acreditam que isso é inevitável, ou que é "dos males o menor", ou a "vontade suprema", ou porque nem percebem a exploração)".

${ }^{7}$ Vale ressaltar que não é escopo deste texto realizar uma análise aprofundada deste programa, o que ensejaria outro tipo de pesquisa e delineamento metodológico.
} 
figuram tempo e espaço de exercício da cidadania sitiada nos limites do sistema (capitalista)? Em outras palavras, teria o PST uma capacidade de transformação/emancipação humana ou seria ele uma ferramenta para arrefecer os "efeitos colaterais" e/ou mazelas sociais desta sociedade?

Diante do exposto até esse momento, trazemos alguns apontamentos que poderiam simbolizar a emancipação política do esporte, tais como: (i) a democratização do acesso e permanência dos cidadãos nos diversos espaços existentes e ainda a serem construídos nas comunidades brasileiras; (ii) o desenvolvimento de políticas públicas que modifiquem a lógica de "cidade empresarial", que dificulta o acesso à própria cidade e ao esporte como um direito e valoriza o acesso pela lógica do mercado (CASTELLANI FILHO, 2014); e (iii) a superação da mistificação do esporte como instrumento de redenção das mazelas sociais (violência, drogas, trabalho infantil etc.), ao compreendê-lo como bem cultural, como uma "necessidade humana" (ATHAYDE, 2014).

Neste sentido, trazemos o exemplo do PST da cidade de Criciúma/SC, coordenado pela $\mathrm{UNESC}^{8}$, como exemplo de possibilidades emancipatórias tendo o esporte e as políticas sociais como molas propulsoras. No artigo Programa Segundo Tempo: uma política para a emancipação humana, Colombo et al. (2012) procuram trazer a experiência deste núcleo do PST como uma possibilidade diferente de utilização desse programa (historicamente vinculado a uma perspectiva reprodutivista e ligado à iniciação e formação para o esporte em última análise). A concepção traçada pela UNESC fundamenta-se "na ideia de que a cultura corporal (em especial o esporte), como construção social e histórica da humanidade, pode e deve ser dialeticamente tratada como ferramenta de luta na perspectiva da emancipação humana" (COLOMBO et al., 2012, p. 15).

Os pontos a se ressaltarem dessa proposta são: as orientações metodológicas ${ }^{9}$ construídas neste núcleo (que vão muito além das propostas pelo Ministério do Esporte), e a tendência crítico-superadora ${ }^{10}$ que orienta teoricamente a práxis pedagógica e as diversas atividades relacionadas ao universo da cultura corporal de movimento. No entanto, o ponto alto, a nosso ver, é a participação da comunidade nos processos de formulação e controle do programa e a inserção deste na comunidade como um agente mobilizador e politizador a partir de uma perspectiva emancipatória, possibilitando debates que vão para além do esporte e que discutem a realidade social.

É importante ressaltar que essas indicações, de forma alguma, esgotam ou findam as discussões para o contexto ora apresentado, sendo apenas mediações iniciais e, portanto, insuficientes.

\section{Considerações finais e transitórias - possibilidades no esporte na luta pela emancipação humana}

Se a cidadania plena e a emancipação humana estão condicionadas a outra sociabilidade, não seria justo cobrar do esporte a consolidação desses projetos. Histórica e contemporaneamente, observamos que o potencial emancipatório do esporte é limitado. Numa analogia

\footnotetext{
${ }^{8}$ Universidade do Estremo Sul Catarinense.

${ }^{9}$ Incorrem em seis orientações básicas: 1. O acesso deve ser garantido com recursos e estrutura. 2. A permanência decorre (não exclusivamente!) de uma metodologia que rompa com os paradigmas do rendimento. 3. Consideração dos conhecimentos sobre o esporte a partir do princípio da totalidade. 4. Romper com a organização de eventos descontextualizados, não-problematizadores $\mathrm{e}$ pontuais. 5. Identificar-se com as culturas/tradições/subjetividades de cada localidade. 6. Articulação com organização comunitária (COLOMBO et al., 2012, p. 16).

${ }^{10}$ Esta tendência pedagógica da Educação Física tem no conhecimento, entendido como "a compreensão inteligível da realidade, que o sujeito humano adquire através de sua confrontação com essa mesma realidade" (LUCKESI apud COLOMBO et al, 2012, p. 16), o centro do processo de educação.
} 
imperfeita, o esporte e seus diversos agentes estariam, talvez, procurando uma pertença emancipação política, mas distante a passos largos da luta pela emancipação humana.

Entretanto, Ivo Tonet (2005) traz uma reflexão sobre educação, cidadania e emancipação humana que nos inspirou. Sua tese é de que a cidadania não deveria ser o objetivo maior da educação (como se ela fosse sinônimo de liberdade efetiva e plena), mas sim da emancipação humana, que é efetivamente sinônimo de liberdade plena. Nesse sentido, o autor não se coloca contra a relação entre cidadania e educação, mas delimita de modo claro que a cidadania deve ser um meio e não o fim desse processo. Nas palavras do próprio autor "a cidadania pode e deve ser articulada, como uma mediação para emancipação humana, com a educação" (TONET, 2005, p. 144).

Assim, inspirados neste autor, fazemos a seguinte indagação: há possibilidade de o esporte, ao associar-se à cidadania, ser uma mediação para a emancipação humana? Sem idealizações, o que queremos problematizar aqui é se a democratização do acesso ao esporte, por meio das políticas públicas sociais, e a percepção dele como um fenômeno humano, social e cultural podem favorecer reflexões acerca da realidade social na perspectiva da emancipação humana. Neste ínterim, torna-se importante ressaltar que essa relação não se iguala às possibilidades sugeridas por Tonet (2005). Contudo, pelo fato de os dois fenômenos estarem inseridos numa mesma totalidade - a sociedade burguesa - e serem fenômenos sociais modernos, percebemos existir um potencial emancipatório no esporte assim como há na educação, resguardando as particularidades e vicissitudes de ambos.

Neste contexto, uma primeira possibilidade seria associar o esporte a um bem social e cultural, construído pelos seres humanos em seu processo histórico e, sendo assim, um bem de todos. Para tanto, democratizar o esporte é algo determinante e este deveria ser o horizonte do poder público! Isto significa ampliar o acesso ao esporte por meio de vivências reais e autônomas e que relacionem trabalho e cultura de uma forma única, seja na escola, seja nas praças, seja em outros espaços possíveis no cotidiano de cada brasileiro.

Assim, torna-se preponderante contrapor-se (no sentido de apresentar o contraditório) a aspectos presente no esporte contemporâneo, como sua mercantilização e espetacularização ${ }^{11}$. Não nos referimos apenas ao campo do esporte de alto rendimento/espetáculo neste quesito, mas à "penetração da lógica do mercado no âmbito das atividades físico-desportivas de lazer, realizadas (consumidas) por camadas cada vez mais amplas da população" (BRACHT, 2005, p. 92).

Uma segunda possibilidade seria utilizar-se das possibilidades abertas pelo caráter contraditório das políticas sociais. Tais políticas reproduzem e por vezes aprofundam as relações sociais capitalistas, mas, ao mesmo tempo, possuem a capacidade de ser um espaço de aglutinação, reflexão e organização política. Essa feição conflitante pode produzir um ambiente propício ao florescimento do senso crítico quanto à realidade social e aos reais motivos da desigualdade estrutural em nossa sociedade, como no exemplo trazido pelo PST em Criciúma.

Ressaltamos, neste fim, que a perspectiva universalizante das políticas sociais e a constituição de um cidadão pleno em todas as suas dimensões passam necessariamente pela superação da ordem vigente. O esporte neste contexto, fruto das contradições desta sociedade, não deve ser negado na perspectiva da emancipação humana, mas, sobretudo, socializado e, na medida do possível, ressignificado nas suas diversas possibilidades no intuito de criar nos indivíduos condições reais e autônomas para objetivar-se na luta pela cidadania plena.

\footnotetext{
${ }^{11}$ A indústria cultural possui um papel central nestas ações, com sua intenção última de procurar novos nichos de acumulação e de ampliação dos já existentes para a reprodução do capital. 


\section{Referências}

ABREU, H. Para além dos direitos: cidadania e hegemonia no mundo moderno. Rio de Janeiro: Editora UFRJ, 2008.

ATHAYDE, P. F. A. O ornitorrinco de chuteiras: determinantes econômicos da política de esporte do governo Lula e suas implicações sociais. 2014. 415 f. Tese (Doutorado em Política Social) - Programa de Pós-graduação em Política Social, Departamento de Serviço Social, UnB, Brasília, 2014.

BARBALET, J. M. A cidadania. Lisboa: Estampa, 1989.

BEHRING, E. R.; BOSCHETTI, I. S. Política social: fundamentos e história. 9. ed. São Paulo: Cortez, 2011.

BOSCHETTI, I. S. Assistência social e trabalho no capitalismo. São Paulo: Cortez, 2016.

BRACHT, V. Sociologia crítica do esporte: uma introdução. 3. ed. Ijuí: Ed. Unijuí, 2005.

BRASIL. Decreto-Lei n. ${ }^{\circ}$ 3.199, de 14 de abril de 1941. Diário Oficial da União, Rio de Janeiro, RJ, 16 abr. 1941. Seção 1, p. 000. Disponível em: <http://www2.camara.leg.br/legin/fed/declei/1940-1949/decreto-lei-3199-14-abril-1941413238-publicacaooriginal-1-pe.html>. Acesso em: 22 nov. 2016.

. Decreto-Lei n. ${ }^{\circ}$ 6.251, de 8 de outubro de 1975. Diário Oficial da União, Brasília, DF, 9 out. 1975. Seção 1, p. 13460. Disponível em: <http://www2.camara.leg.br/legin/fed/lei/1970-1979/lei-6251-8-outubro-1975-357712publicacaooriginal-1-pl.html>. Acesso em: 22 nov. 2016. ral, 2005.

Constituição da República Federativa do Brasil de 1988. Brasília: Senado Fede-

Ministério do Esporte. Diretrizes do Programa Segundo Tempo. Brasília: Governo Federal, Ministério do Esporte, 2014.

BROHM, Jean-Marie. Sociología política del deporte. México: Fondo e Cultura Económica, 1982.

CASTELLANI FILHO, L. O Estado brasileiro e os direitos sociais: o esporte. In: HÚNGARO, E. M.; DAMASCENO, L. G.; GARCIA, C. C. (Org.). Estado, política e emancipação humana: lazer, educação, esporte e saúde como direitos sociais. Santo André: Alpharrabio, 2008.

Megaeventos esportivos no Brasil: de expressão da política esportiva brasileira para a da concepção neodesenvolvimentista de planejamento urbano. Motrivivência, Florianópolis; v. 26, n. 42, p. 98-114, jun. 2014.

COLOMBO, B. D. et al. O Programa Segundo Tempo: uma política pública para emancipação humana. Motrivivência, Florianópolis, v. 24, n. 38, p. 12-23, jun. 2012. 
COUTINHO, C. N. Contra a corrente: ensaios sobre democracia e socialismo. 2. ed. São Paulo: Cortez, 2008.

1999.

Notas sobre cidadania e modernidade. Perspectivas, São Paulo, v. 22, p. 41-59,

IAMAMOTO, M. O Brasil das desigualdades: "Questão social", trabalho e relações sociais. Revista SER Social, v. 15, n. 33, p. 326-342, Brasília, jul./dez. 2013.

IASI, M. Ensaios sobre consciência e emancipação. 2. ed. São Paulo: Expressão popular, 2011.

MANDEL, E. O capitalismo tardio. São Paulo: Abril Cultural (Os economistas), 1982.

MARSHALL, T. H. Cidadania, classe social e status. Rio de Janeiro: Zahar, 1967.

MARX, K. Sobre a questão judaica. São Paulo, Boitempo, 2010.

O desafio e o fardo do tempo histórico: o socialismo no século XXI. São Paulo: Boitempo, 2007.

PRONI, M. W. Esporte-espetáculo e futebol-empresa. 1998. 262 f. Tese (Doutorado em Educação Física) - Faculdade de Educação Física, UNICAMP, Campinas, 1998.

ROUYER, Jacques. Pesquisa sobre o significado humano do desporto e dos tempos livres e problemas da história da educação física. In: ADAM Y. et al. Desporto e movimento humano. Lisboa: Seara Nova, 1977.

TONET, I. Educação, cidadania e emancipação humana. Ijuí: Ed. Unijuí, 2005.

VEROZEZ, L.. F. C. Quando o Estado joga a favor do privado: as políticas de esporte após a Constituição Federal de 1988. 2005. 376 f. Tese (Doutorado em Educação Física) - Faculdade de Educação Física, UNICAMP, Campinas, 2005.

Recebido em: 24/11/2016

Revisado em: 30/03/2018

Aprovado em: 14/07/2018

Endereço para correspondência:

pedroavalone@gmail.com

Pedro Avalone Athayde

Universidade de Brasília- UnB

Campus Universitário Darcy Ribeiro

Brasília, DF, 70297-400 